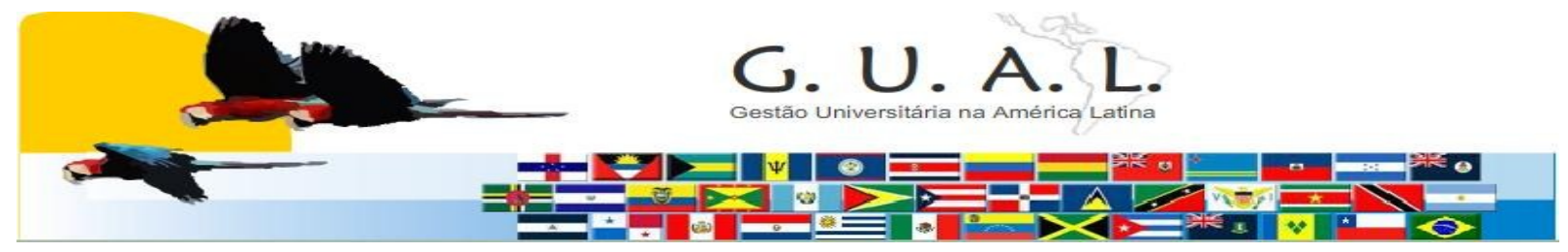

ISSN 1983-4535

\title{
UNIVERSIDADE E MODIFICAÇÃO ORGANIZACIONAL - DO MODELO BUROCRÁTICO À ORGANIZAÇÃO INTENSIVA DE CONHECIMENTO
}

\section{THE UNIVERSITY AND THE ORGANIZATIONAL CHANGE - FROM THE BUREAUCRATIC PATTERN TO THE INTENSE ORGANIZATION OF KNOWLEDGE}

Adelcio Machado dos Santos, Doutor Universidade do Alto Vale do Rio do Peixe - Uniarp adelcio@redelnet.com.br

Maurício Fernandes Pereira, Doutor Universidade Federal de Santa Catarina - UFSC mpereira@cse.ufsc.br

Recebido em 10/novembro/2011

Aprovado em 08/fevereiro/2012

Sistema de Avaliação: Double Blind Review

Esta obra está sob uma Licença Creative Commons Atribuição-Uso. 


\title{
RESUMO
}

Este artigo enfoca a educação superior, especificamente nas universidades, agora inseridas em um contexto de globalização, buscando entender como essas organizações surgidas na Idade Média, passando pelas transformações da Modernidade e do Iluminismo, chegaram ao século XXI, enfrentando os reptos de sua sustentabilidade, a partir de valores, missão e tradição cultural, mantidos ao longo dos séculos. Em concordância com essa visão, alguns autores defendem que um dos elementos para compreender o processo de mmodificação pelo qual passa a sociedade é o aumento progressivo da dependência dos países, dos governos, das empresas e dos indivíduos em relação ao conhecimento. Nações e indivíduos estão percebendo sua condição de dependência uns em relação aos outros e o papel central que o conhecimento possui, sendo necessário para isso que se dê uma nova visão quanto à organização intensiva do conhecimento. Destarte, esse mostrar o modo como as organizações partilham o conhecimento, e como este é facilitado pela divulgação através dos meios de comunicação e pela informática, para isso será apresentado um breve histórico da universidade, para que seja entendido de que maneira essas organizações se comportam com as mudanças tecnológicas e estruturais dos novos tempos. Onde poderá ser observado que a aludida modificação organizacional pode assegurar a sustentabilidade, na conjuntura de diuturnas transformações. Para atingir tais objetivos será utilizada a pesquisa bibliográfica, como metodologia de pesquisa. Nessa pesquisa evidenciou-se que a universidade é uma organização complexa, onde a burocracia em determinados momentos é um empecilho para o crescimento, fazendo-se mister que os gestores utilizem de todo conhecimento para geri-la.

Palavras-chave: Universidade. Burocracia. Modificação organizacional.

\begin{abstract}
This article focus on upper education, specifically at universities, now inserted in a context of globalization, searching to understand how these organizations, which rose in the Middle Age, going through transformations of modernity and of the Illuminism, have reached the XXI Century, facing challenges of their sustainability, from values, mission and cultural tradition, kept throughout the centuries. According to this vision, some authors defend that one of the elements to understand the process of change through which the society goes is the progressive raise of the dependence of the countries, of governments, of companies and of individuals in relation to knowledge. Nations and individuals perceive their condition of interdependence towards each other and the central role knowledge performs, being necessary for this that a new vision concerning the knowledge intensive organization be given. Thus, this showing of how organizations share knowledge and how this is made easier by the quick spreading through the media and cyberspace, a brief history of the university will be presented, so that one can understand which way these organizations behave with technological and structural changes of new days, when it will be possible to observe that the mentioned organizational change can assure sustainability in the conjuncture of long-lasting transformations. In order to reach these objectives, the methodology of bibliographical research will be used. In this research it was evident that university is a complex organization, where bureaucracy in certain moments is an obstacle to growth, being necessary for this that managers and/or administrators use all their organizational knowledge to run it, because of this, the importance of organizational changing in administration.
\end{abstract}

Keywords: University. Bureaucracy. Organizational change. 


\section{INTRODUÇÃO}

Os estudos sobre organizações, ao longo da história, levantaram diversas teorias. A sobrevivência das organizações depende de diversas ações diretas, tanto interna como exogenamente, seguida de suas crenças, valores e sentimentos.

Na década de 1960, nos Estados Unidos da América, a estratégia organizacional nascia como disciplina híbrida, com influências de disciplinas como a Sociologia e a Economia, apresentando uma evolução de ramos específicos da teoria das organizações, no contexto de formação e consolidação de escolas de administração como escolas profissionais inseridas no ambiente mais complexo das universidades estadounidenses, de acordo com entendimento de Vasconcelos (2007, p. 4).

Surge também a burocracia, que, na linguagem coloquial, muitas vezes assume uma conotação pejorativa, sendo rotineiramente associada à ineficiência, ineficácia, atrasos, confusão, autoritarismo, privilégios e a outros atributos negativos. Por outro lado, as organizações modernas são descritas como uma ruptura fundamental com esses atributos da burocracia, tanto em parte da literatura especializada em administração, como na grande maioria da imprensa de grande público.

O presente artigo tem como objetivo mostrar o modo como as organizações partilham o conhecimento, e como este é facilitado pela divulgação através dos meios de comunicação e pela informática, para isso será apresentado um breve histórico da universidade, para que seja entendido de que maneira essas organizações se comportam com as mudanças tecnológicas e estruturais dos novos tempos. Para tanto, será analisada a administração científica, a teoria da burocracia, a escola estruturalista e a era industrial neoclássica, essas escolas apresentam subsídios para melhor entendimento do tema em questão.

Quanto à Metodologia empregada, registra-se a Pesquisa Bibliográfica, cuja base filosófica, de acordo com entendimento de Pacheco Jr, Pereira e Pereira Filho (2007), diz respeito aos fundamentos históricos de pensamento adotado na pesquisa científica e deve ser declarada, visando a mostrar a corrente adotada.

Sobre a pesquisa bibliográfica, Cervo e Bervian (1983, p. 55) acrescentam que essa explica um problema a partir de referenciais teóricos publicados em documentos. Podendo ser realizada de maneira independente ou como parte da pesquisa descritiva ou experimental. Os 
dois casos procuram conhecer e analisar as contribuições culturais ou cientificas existentes sobre um determinado assunto, tema ou problema.

Utilizar-se-á nesse estudo o método dialético, porquanto essa é uma forma de pensar em que há a necessidade de descrever e confrontar os postos para conhecer os fenômenos, porém, não de uma forma estática. É preciso, uma definição espacial e histórica dos contrários, a fim de ser possível situá-los como reveladores do conhecimento.

\section{NOVO CENÁRIO}

Temas como gestão digital, empresas hipermodernas, economias pós-industriais e outros freqüentemente aparecem na imprensa, sugerindo que o "velho" modelo de comando e controle estaria definitivamente ultrapassado e seria inexoravelmente substituído por um novo e revolucionário, fundado no engajamento dos empregados e na descentralização das decisões (VASCONCELOS, 2007).

Pereira e Fonseca (1997) salientam que a função dos administradores nas organizações apresenta um caráter decisório. Sendo assim, as decisões afetam de maneira direta a sobrevivência da organização e a vida das pessoas que se encontram envolvidas em torno dela, sejam elas colaboradores, acionistas, fornecedores ou clientes.

Porto Gonçalves (apud GUIMARÃES, RECHTMAN e NETTO, 2004) salienta que na atualidade, o mercado exige da empresa uma postura calcada no tempo presente, sem amarras ao passado, projetada para o futuro. Dela também se espera que seja atrativa para investidores, fornecedores e clientes. Para isso, precisa estar atenta às permanentes transformações tecnológicas, além de pronta a satisfazer as necessidades dos consumidores, sempre ansiosos por novidades. Deve, além disso, incorporar à sua cultura administrativa a idéia de que necessita adequar-se às novas realidades: mudar para não ser superada tanto pela concorrência interna como pela externa.

Vasconcelos (2007) assinala também que, composta por indivíduos com formas diferentes de pensar, valores e modos de agir, a organização evolui graças à interação destes, que permite o surgimento do novo a partir do contraponto de várias visões de mundo. Com o apoio da tecnologia de informação avançada, este processo requer a articulação e a transferência progressiva do conhecimento tácito e do conhecimento explícito a um número crescente de indivíduos na organização, que devem questionar seus modelos mentais e seus comportamentos, e modificá-los de forma a incorporarem as novas idéias e perspectivas. 
A conscientização para esse novo cenário universal e a adaptação a ele são fundamentais para as organizações alcançarem seus objetivos, para as organizações, trata-se de uma questão de sobrevivência. Na opinião de Alencar (1995, apud AMBONI e TEIXEIRA, 2008), já se faz presente a demanda de novas estruturas, por novos procedimentos administrativos e por novas lideranças, dotadas daqueles requisitos da era da informação. Para as nações, uma administração alheia a essa nova realidade levará qualquer uma delas a crescer muito menos que o seu potencial permite, da mesma maneira a oferecer uma qualidade de vida a seus cidadãos muito aquém de suas potencialidades e a tornar-se dependente.

Se, de um lado, existe o poder do conhecimento do capital humano como uma das molas propulsoras das transformações organizacionais, de outro, o que se observa é a consciência de que não basta ter capital humano com conhecimento e visão prospectiva, quando se tem na organização um líder com visão introspectiva e com perfil de gestor de recursos (AMBONI, 1995, apud AMBONI e TEIXEIRA, 2008).

Já é um lugar comum sustentar que a humanidade vive um processo muito profundo de transformação, do qual uma das características fundamentais é a centralidade que adquire o conhecimento na conformação da nova estrutura social. O conhecimento e a informação têmse convertido na base dos processos produtivos e o tempo necessário para que o conhecimento científico se traduza em aplicações tecnológicas é significativamente mais curto que no passado.

Todavia, ademais deste impacto do conhecimento sobre o processo produtivo, também se tem acrescentado a importância do conhecimento e da informação em diversos âmbitos do desempenho cidadão. As conseqüências sociais das investigações sobre o genoma humano constituem eloqüente exemplo da significativa responsabilidade do conhecimento científico - e de seus possuidores - na sociedade atual, conforme enfatiza Tedesco (2006).

Por outro lado, o otimismo inicial com o qual se analisaram as conseqüências sociais do novo papel do conhecimento tem desaparecido. Aprendeu-se rapidamente que as potencialidades democráticas do uso intensivo de conhecimentos podem não vir a acontecer. As tendências ao aumento da desigualdade e da exclusão social indicam que uma sociedade e uma economia baseadas no uso intensivo de conhecimentos podem ser muito mais inequitativas que uma sociedade e uma economia baseadas no uso de outros fatores (COHEN, 1997, apud TEDESCO, 2006). 
Nesse contexto, o papel das universidades enquanto instituições responsáveis por produzir e disseminar conhecimentos deve ser analisado, no marco de tais transformações globais.

Para Tedesco (2006), na definição da agenda de discussão sobre o papel das universidades, aparecem, ao menos, duas categorias que permitem incluir os temas mais significativos. A primeira delas se refere a todos os problemas relativos ao acesso ao conhecimento; a segunda se refere às relações entre universidade, Estado e sociedade.

\subsection{A Universidade}

Abrahamson (2006, p. xv) afirma que "educar não é encher um balde, mas acender uma fogueira". Educar é um processo de aprendizado que envolve despertar o conhecimento, não introduzi-lo, sendo assim, a educação superior é responsável por promover mudanças para que o educando obtenha sucesso pessoal.

A universidade surgiu na Idade Média, com o nome de studium. Graças ao prestígio que alcançaram com o decorrer dos tempos, nos fins do século XII, algumas escolas ou studia passaram a permitir que aqueles que nelas se formassem pudessem lecionar em qualquer outro lugar. Com isto ganharam o nome de studia generalia. O termo Universitas, que significa anteriormente qualquer corporação ou comunidade, passou a ser usado como sinônimo de studia generalia. Tal palavra significava faculdade ou conjunto de corpos de ensino que formavam a Universidade (LISBOA, 1993).

Esse autor também acrescenta que as universidades foram se multiplicando na Idade Média, tornando-se portadoras do saber. O espírito delas, de fortalecimento, de unidade serviu para a formação dos Estados Nacionais. A partir do século XV, a universidade tomou outros rumos, quer pelo sentido das nacionalidades, pela centralização do poder nacional, quer pelos novos descobrimentos. Como a instituição cultural a Universidade Medieval pôde considerar o seu ciclo encerrado no início do século XVI, junto com muitas mudanças de entendimento e percepção da instituição, demonstrando assim, uma grande mudança organizacional.

As primeiras universidades brasileiras datam dos anos 1930; no entanto, as primeiras escolas superiores do Brasil foram criadas por D. João VI, a partir de 1808. O Brasil, ao contrário das colônias Ibéricas, não teve a presença de universidades no período colonial. Portanto, não há dúvida de que esse país é herdeiro da experiência universitária portuguesa, ou mais especificamente de sua Universidade de Coimbra (ROMANELLI, 1991). 
As instituições contemporâneas que se dedicam à educação superior descendem da universidade do período medieval. As universidades medievais tiveram um princípio religioso e estavam ligadas às escolas das catedrais e dos mosteiros.

Desde então ocorreu um expressivo aumento no número e no tamanho das instituições dedicadas ao ensino superior. O principal produto das escolas superiores é o saber, envolvido com os sistemas tecnológicos, estruturais, psicossociais, políticos e administrativos das universidades, que são expressivamente diversos dos de outras organizações e estão sofrendo suas próprias transformações, diante do crescimento acelerado, fruto da concorrência e da qualidade, que a globalização impõe.

A universidade tem características estruturais e operacionais que tornam seu processo mais complexo que as demais organizações. O que caracteriza genericamente a universidade é o conceito de universalidade do conhecimento, a partir do qual ele desenvolve suas atividades.

A universidade deve ainda, propiciar à comunidade uma educação de qualidade, procurando formar cidadãos do mundo, com capacidade de atuar com segurança, em parceria e em regime de cooperação, numa sociedade na qual as contradições e inseguranças são acentuadas e presentes no cotidiano. Para tal, deve considerar o homem como um todo, sem a tradicional separação do corpo e da mente, o que implica um redimensionamento curricular (LAMPERT, 2000).

Esse autor afirma ainda que a compartimentação e a desarticulação devem ser substituídas pela integração e articulação na teoria e na práxis. A interdisciplinaridade é uma alternativa que deve ser utilizada em todos os níveis e modalidades de ensino, em vez de formar profissionais acríticos, alienados, tecnólogos. Deve priorizar a reflexão, a criação, a construção, a reconstrução, o pensar, o repensar, o amor à humanidade e a natureza.

Greco (2002) certifica que como instituições sociais, as universidades têm características próprias, decorrentes das comunidades onde se localizam, das pessoas a elas vinculadas, da época a que pertencem, das contingências nacionais, regionais e locais que as envolvem e da capacidade de cada um desses fatores relacionarem-se com os demais.

$\mathrm{Na}$ atualidade, a universidade encontra-se inserida em um contexto de globalização, buscando entender como essa instituição, surgida na Idade Média, passando pelas transformações da modernidade e do iluminismo, chega ao século XXI, enfrentando os desafios de sua sustentabilidade, a partir de valores, missão e tradição cultural, mantida ao longo dos séculos. 
Guedes (2000) alega que o papel fundamental das universidades é ajudar na passagem do saber espontâneo para o saber científico. O saber popular tradicional não dá conta dos fenômenos do mundo atual que se encontra numa construção mediatizada pelas teorias científicas, conseqüentemente, distante da percepção ingênua.

O principal papel, portanto, das universidades, segundo Guedes (2000) é oferecer elementos teóricos necessários para que os indivíduos possam olhar o mundo de forma crítica e possam enxergar fenômenos para além da percepção ingênua.

Considerando estes enunciados, pode-se afirmar que na atualidade, dificilmente um indivíduo trabalha, defende seus interesses e mesmo se diverte, de modo isolado. O ser humano encontra-se inserido em organizações, que coordenam seu trabalho, seu estudo, seus interesses. Sua organização pode possuir caráter econômico, político, religioso e cultural, sendo que cada caráter destes pode se justapor, se intercruzar, se interpenetrar, por meio de relações de cooperação e conflito, dependência e interdependência (MUNIZ et al, 2001).

Lampert (2005) acrescenta ainda que a universidade, dentro de uma nova visão de mundo, precisa estar aberta às inovações e contradições que a tríade ciência/tecnologia/indústria desenvolve. A universidade não pode ser uma torre de marfim, obsoleta, voltada ao passado. Ademais da reprodução de conhecimento, a sua incumbência principal está em gerar ciência e tecnologia, ao mesmo tempo em que terá a tarefa de conceber e trabalhar a complexibilidade dos fenômenos, a pluralidade ideológica.

A universidade não poderá enfocar a unilateralidade, mas considerar a bipolaridade como forma de analisar o desenvolvimento que, de um lado, traz benefícios, conforto e bemestar a poucos, e, por outro, destrói a natureza, a maior riqueza da humanidade, e produz a atomização dos indivíduos, que perdem sua identidade, tornando-se objetos manipulados e dominados pela máquina (LAMPERT, 2005).

A simbologia da expressão "universidade" e a ênfase na imagem institucional imposta aos seus programas permitem leituras diversas: abuso de linguagem, estratégia mercadológica, modismo, crítica ao ensino tradicional e seu distanciamento da realidade, ou modalidade avançada de educação corporativa em sintonia com a gestão de pessoas e alinhada com as competências e os objetivos organizacionais. No âmbito dos cursos de capacitação gerencial, em nível de graduação e de pós-graduação, a tendência é de estreitar as parcerias com as instituições de ensino superior tradicionais, por isso, vê-se a importância da administração científica (ALPERSDETD, 2001). 


\subsection{Administração científica}

A Administração científica combina ciência em lugar de empirismo; harmonia em lugar da discórdia; cooperação em lugar do individualismo; rendimento máximo em lugar da produção reduzida; desenvolvimento de cada homem, a fim de alcançar maior eficiência e prosperidade (MUNIZ; FARIA, 2001). Essa é de grande importância, pois é onde as organizações passam por modificações.

De acordo com Corrêa (2003), a administração científica, no período da ênfase nas tarefas, é marcada pela primeira tentativa de desenvolver uma teoria da administração para resolver problemas industriais, representa a preocupação com as operações e tarefas a serem desempenhadas pelas pessoas que trabalham numa organização. Isto foi iniciado pelo engenheiro Taylor (1856-1915), no início do século XX, esse tentava acabar com o desperdício e a improvisação nas indústrias americanas.

Taylor destaca que essa fase foi denominada de 'administração científica' porque objetivava quebrar as tarefas em subtarefas elementares e trabalhar extensivamente para tornar cada uma dessas tarefas mais eficientes.

Raimundo (1992) destaca ainda que, Taylor sustentou que para esses princípios dar certo, se fazia necessário uma revolução mental total por parte da administração e dos operários da organização. Em vez de entrarem em desacordo para saber quais eram os lucros, ambas as partes deveriam procurar aumentar a produção. Para Taylor o setor administrativo e os operários tinham um interesse comum no aumento da produtividade.

Expoente da abordagem clássica da Administração, Henry Fayol também engenheiro, que por volta de 1916 passou a idealizar a gestão da empresa a partir de determinadas funções fundamentais. Stoner (1982) assegura que é possível reconhecer em Fayol o fundador da escola clássica da administração, por ter sido ele o primeiro a sistematizá-lo.

A teoria de Fayol representou um progresso a teoria de Taylor, através de sua tentativa de pensar a empresa como um todo, onde acrescenta um novo elemento a Teoria Geral da Administração, na teoria clássica: a composição da empresa, o que significou um alargamento dos horizontes.

No entanto, a forma como a empresa ainda era vista tinha por base o extremo racionalismo. Nenhuma pessoa até então havia se dado conta de que a empresa é constituída também por indivíduos (STONER, 1982). 


\subsection{Teoria da burocracia - escola estruturalista}

A Teoria Burocrática desenvolveu-se na década de 40. O precursor desta teoria, cuja definição consiste em um sistema social, organizado mediante normas escritas, que visa à racionalidade e à igualdade no tratamento de seu público, foi Max Weber (MUNIZ; FARIA, 2001).

Para melhor entendimento do tema, faz-se necessário evidenciar o pensamento de Weber, para esse pensador, a burocracia moderna compreende uma série de características específicas, tais como: a) regras rígidas e impessoalidade; b) hierarquia; c) documentação e registro; d) especialização e divisão do trabalho; e) continuidade e controle (WEBER, 1982, p. 243).

$\mathrm{Na}$ área da Administração, Muniz e Faria (2001) explicam que Weber desenvolveu seu trabalho sobre três aspectos: aceitação da validade das idéias em que repousa a autoridade racional-legal, organização fundamental necessária para o exercício da autoridade racionallegal e exercício da autoridade racional-legal no quadro administrativo.

A Teoria Burocrática desenvolveu os estudos de poder e de autoridade como componentes integrantes do cargo e da estrutura organizacional. Entretanto, a centralização da autoridade para conseguir manter o controle, a ênfase na fidedignidade do comportamento dos burocratas, a dependência dos regulamentos, no intento de impor uniformidade, e a aplicação de políticas objetivas resultaram em efeitos que não tinham sido previstos e normatizados, revelando conflitos organizacionais.

Essas conseqüências decorreram do fato de Weber ter se preocupado com as relações formais entre os elementos da burocracia, e não com o aspecto informal da organização e os fatores humanos e sociais do comportamento, gerando a formação do "Homem Burocrata" (MUNIZ; FARIA, 2001).

A partir de então, verificou-se a ocorrência da desburocratização nas organizações modernas, sendo que desburocratização significa diminuir o grau de intensidade das dimensões burocráticas.

Weber havia idealizado uma organização que não conseguia funcionar com o rigor determinado pelas características essenciais da burocracia, gerando às imprevisões ou disfunções cujo prejuízo evidencia-se no desempenho das tarefas, e a não execução dos objetivos da empresa. 
Essa fase foi antecessora da era industrial neoclássica que trouxe inovações para a administração e a indústria, como será observado no tópico seguinte.

\subsection{Era industrial neoclássica}

A era industrial neoclássica estendeu-se no período de 1950 até 1990 significando uma etapa de grandes transformações no mundo dos negócios. Com o fim da Segunda Guerra Mundial as organizações estavam libertas para os seus produtos e serviços originais, e o desenvolvimento tecnológico, também se proporcionou condições básicas para as organizações produzirem, em grandes escalas, uma variedade de produtos e serviços inovadores. Os mercados locais tornaram-se regionais, nacionais e internacionais (BOOG, 2000).

Esse autor também destaca que para operar com essa complexidade, as organizações precisavam de inovações e mudanças. A mudança ambiental trouxe novos e amplos desafios, como a rápida expansão dos mercados, produtos e processos, tecnologias e, o surgimento de potências emergentes como o Japão e os Tigres Asiáticos.

Observou-se nessa época ainda que novas realidades começam a mostrar seus contornos, através da globalização da economia, com novos conceitos como qualidade total, produtividade, competitividade, formas de sobrevivência empresarial (KANAANE, 2000).

Muniz e Faria (2001) apresentam as características básicas dessa era, que são: a ênfase na prática da administração, utilização do pragmatismo em busca de resultados concretos, baseados nos conceitos teóricos da administração. Além disso, a reafirmação dos postulados clássicos, com o retorno de um estudo desenvolvido pela Teoria Clássica, só que buscando dar uma reestruturação de acordo com a situação atual.

Essas teorias estudadas até então servem como base para melhor entendimento das mudanças na sociedade e na gestão educacional, tema que será abordado no tópico seguinte.

\subsection{Mudanças na sociedade e gestão educacional}

Gestão universitária é um tema oportuno e relevante de interesse de diferentes segmentos da comunidade acadêmica, que em geral, envolvem-se na questão da Gestão em organizações universitárias, cujo relevante papel de construir e disseminar o saber, a ciência e a tecnologia são essenciais à vida humana (COLOSSI, 2004).

Penin e Vieira (2002) defendem que um dos elementos para compreender o processo de mudança pelo qual passa a sociedade é o aumento progressivo da dependência dos países, 
dos governos, das empresas e dos indivíduos em relação ao conhecimento. O modo como os homens partilham o conhecimento, gerando outros, é facilitado pela sua rápida divulgação através dos meios das tecnologias de comunicação e informação.

Nesse contexto organizacional, insere-se as instituições de ensino. De acordo com Penin e Vieira (2002), advertem que os métodos de planejamento, gestão, inovação e avaliação na educação agregam conhecimento e reflexão da realidade, conhecimento e reflexão teórica, sendo necessária a modificação desses de modo a proporcionar a direção do exercício pedagógico que realize a intencionalidade educativa / formativa.

Observa-se que a gestão educacional exerce um papel fundamental dentro das escolas, em um mundo globalizado, caracterizado por grandes mudanças. De acordo com Drucker (2001), as áreas do conhecimento estão em constante mudança. As faculdades, departamentos e disciplinas existentes não serão adequadas por muito tempo.

A busca do conhecimento, bem como seu ensino, tem sido costumeiramente dissociado de sua aplicação. Ambos foram organizados por temas, ou seja, segundo o que parecia ser a lógica do próprio conhecimento. As faculdades e os departamentos das universidades, títulos acadêmicos, especializações juntamente com toda a organização do ensino superior, têm se concentrado nos temas (DRUCKER, 2001).

Na opinião de Demo (1998), o futuro será dominado pela "teleducação", ou seja, mediada por alguma forma de instrumentação eletrônica, sobretudo pela interligação da televisão com internet. $\mathrm{O}$ desafio que tem de superar o instrucionismo, para atingir patamares mais nítidos da aprendizagem. No pano de fundo, segundo o autor, está a "sociedade do conhecimento" e, no contexto do mercado, o capitalismo da mais-valia relativa, que, por si só já exige condições mínimas de competitividade globalizada, passando a valorizar o saber pensar.

Este saber pensar se restringe ao manejo produtivo do conhecimento, não à cidadania, uma vez que as formas liberais de mercado não conseguem colocar a cidadania acima da relação de mercado, por mais que possam fazer uso de linguagens alternativas atraentes. Todavia desvirtua o compromisso com a reconstrução do conhecimento, jamais com sua simples transmissão copiada, reprodutiva. A educação não pode escapar da fascinação tecnológica, já que é no fundo a mesma do conhecimento. Uma vez que foi nos espaços educacionais que o conhecimento mais se desenvolveu, seria de se esperar que o espaço que mais se beneficiaria dele seria a própria educação (DEMO, 1999). 
Esse autor chama a atenção, ao fato de que, na atualidade as instituições educacionais se atrasaram, porque criaram uma tecnologia que corre à velocidade da luz (que são as instrumentações eletrônicas) e não conseguem acompanhá-lo. Acresce a isto que, sobretudo, que o mercado liberal, monopoliza grande parte ou a parte mais decisiva da pesquisa científica. O mercado produz conhecimento inovador, e exclusivamente o que interessa ao mercado, em proporção muito maior que a universidade. Mesmo assim, o próprio fato de que a tecnologia praticamente resolveu o problema da informação, já trouxe o problema contrário das pessoas serem massacradas pela informação excessiva, indica que a parte da educação dedicada a transmitir conhecimento será apropriada por processos informatizados.

$\mathrm{Na}$ contemporaneidade, cada vez mais se organizam o conhecimento e sua busca em torno de áreas de aplicação, e não mais ao redor das áreas que são objetos das disciplinas. De acordo com Drucker (2001) nos últimos tempos o trabalho interdisciplinar tem crescido de maneira acelerada em todos os lugares, movimentando muito mais as energias das universidades e dessa maneira, determinando a sua direção.

As organizações, por sua vez, tentam desenvolver e otimizar sua aprendizagem de diferentes maneiras. Os princípios básicos que norteiam a cultura de uma instituição originam determinados valores de aprendizagem e condicionam a escolha das áreas que receberão mais atenção (DIBELLA; NEVIS, 1999).

$\mathrm{Na}$ sociedade do conhecimento, a escola passa a ter, responsabilidades maiores por desempenho e resultados. Sendo necessário para isso que lhe sejam atribuídas novas especificações. A escola deve proporcionar instrução universal de alto nível, muito além do real significado de "instrução" na atualidade. É preciso que ela impregne os alunos de todos os níveis e de todas as idades de motivação para aprender e de disciplina para o aprendizado contínuo (DRUCKER, 2001).

Da mesma maneira, a escola necessita ser um sistema aberto, acessível às pessoas de elevado grau de instrução e às pessoas que por qualquer motivo não tiveram acesso à instrução avançada quando jovens, devendo proporcionar o conhecimento sob a forma de conteúdo e processo.

Segundo Xavier (1998), o conhecimento e a informação são considerados privilegiados geradores de riqueza, pois: 
Equivalem a ativos como máquinas, dinheiro, prédios, terra, estoques. Mais que isso, é um ativo privilegiado, numa era em que tudo muda rápida e intensamente e os grandes aparatos econômicos de hoje passam a não oferecer nenhum valor estratégico. É na verdade o único ativo que se mantém capaz quando todo o mais entra em crise (XAVIER, 1998, p.09).

Esse autor também acrescenta que o conhecimento foi sendo cada vez mais visto como o grande gerador de riqueza no pós-capitalismo. Ao se analisar o PIB das nações mais desenvolvidas, percebe-se que as maiores parcelas de contribuição migraram da agricultura para a indústria, dessas para os serviços e mais recentemente para tudo aquilo que agrega conhecimento de ponta. Paralelamente, a competição cada vez mais acirrada foi levando as empresas a ampliarem seu grau de profissionalização.

De acordo com Penin e Vieira (2002), essa nova relação dos indivíduos com o conhecimento traz duas conseqüências para a escola brasileira. A primeira consiste no reforço de sua importância social, já que ela ainda é a porta de entrada da maior parte da população, para o acesso ao mundo do conhecimento. De fato, enquanto que grandes quantidades de informações estão acessíveis, uma grande parcela da população permanece excluída da sociedade da informação.

A segunda conseqüência, aliada à perspectiva democratizadora, é a necessidade de a escola repensar seu modo de organização, sua gestão, sua maneira de definir os tempos, os espaços, os meios e o modo de ensinar, isto é, a forma de fazer escola. Assim, é necessário formar uma escola a partir de sua função social, qual seja: “ensinar bem e preparar os indivíduos para exercer a cidadania e o trabalho no contexto de uma sociedade complexa, enquanto se realizam como pessoas" (PENIN e VIEIRA, 2002, p.27).

$\mathrm{Na}$ sociedade do conhecimento é importante referir Gestão do Conhecimento como um processo que permite a inovação e a expansão dos negócios através da criação de valor pelo conhecimento organizado. Passa pelo estudo, discussão e compreensão das características e demandas do ambiente competitivo e entende o conhecimento como o ativo mais importante das empresas, como enfatiza Scharf (2007).

Em consonância com Mohrman e Mohrman (1995, p. 69), “os ambientes organizacionais tem se tornado menos benignos, mais complexos, mais inter-relacionados e mais dinâmicos.” Estas mesmas condições promovem a necessidade para a mudança e ao mesmo tempo dificultam o aprendizado e a mudança ao sobrecarregar a capacidade de processamento da informação dos membros da organização. 
Por isso, importa compreender como as organizações aprendem e como mudam. Estas transformações trouxeram a tona uma nova era, chamada de "Era do Conhecimento", cuja fonte fundamental de riqueza é o conhecimento. Seu impacto na vida das organizações foram grandes mudanças, que deram-se início com o aumento do volume de informações, quando financiou-se a Universidade para os soldados da II Guerra Mundial.

A mudança significa o ato ou efeito de mudar ou mudar-se. Pode ser uma troca ou transferência de algo ou de pessoas. Pode ainda ser qualquer tipo de transformação decorrente de determinados fenômenos ou de modificações de um estado normal de algo ou de um processo (COLOSSI, 2004).

A organização universitária, como uma instituição social a servir a sociedade onde se insere, está sujeita às mudanças e às explosões que caracterizam o mundo organizacional contemporâneo, além de que, caracteriza-se pela necessidade de mudanças para sua sobrevivência, nessa época de grandes transformações. Colossi (2004) destaca que a gestão universitária é particularmente atingida por essa explosão gerencial.

Dibella e Nevis (1999) sustentam que as organizações adquirem conhecimento diretamente pela experiência de seus colaboradores e indiretamente, pela experiência de outras organizações. Porém, a primeira fase do ciclo de aprendizagem pode envolver tanto a criação quanto a aquisição de conhecimento. Como sistemas sociais em que os empregados estão continuamente gerando novas experiências, as empresas têm o potencial de estar aprendendo o tempo todo, quando a aprendizagem torna-se endêmica.

Para as universidades públicas, tais reflexões representam uma oportunidade para reconhecer que as alterações necessárias no sistema educacional devem ser atendidas com rapidez e demandam esforço coletivo de todos os que estão envolvidos no processo de construção educacional, como profissionais, governos e sindicatos, bem como a sociedade como um todo.

No entendimento de Santos (2002), a escola, como instituição social, necessita acompanhar as transformações da sociedade e assumir outras funções contribuindo, em especial, para o desenvolvimento da capacidade de pensar e de atuar com autonomia e compreender e redefinir os objetivos explícitos e latentes do processo de socialização. A escola da sociedade pós-industrial tem a função de desenvolver mecanismos que minimizem as diferenças de origem, mediante a atenção e o respeito pela diversidade.

Existe um grande debate sobre a concepção das atribuições da educação e sobre sua função social, para isso, a Unesco, instituiu a Comissão Internacional sobre a Educação para o 
século XXI, comissão essa que concebeu a educação em seu relatório a partir de princípios que concebem os quatro pilares dessa, a saber: aprender a conhecer, aprender a fazer, aprender a conviver e aprender a ser (PENIN e VIEIRA, 2002).

Colossi (2004) destaca que neste ambiente de mudanças, as organizações passam por grandes transformações em suas estruturas, seus processos e seus produtos. Conceitos tradicionais consolidados ao longo da evolução do pensamento adminsitrativo-organizacional, são substituídos por novos paradigmas face à necessidade de sobrevivência em um mundo globalizado.

Nesse ínterim, a instituição universitária, um tipo especial de organização complexa e caracterizada por sua natureza conservadora, recebe ainda o impacto do ambiente de mudanças globais. Dessa forma, o fenômeno crise-mudança faz parte da rotina organizacional de instituições universitárias (COLOSSI, 2004).

A Administração universitária exerce um papel fundamental na superação da crise que permeia o contexto educacional, de tal forma que se não houver o contínuo aperfeiçoamento do sistema escolar, no nível da administração, a crise tenderá a uma expansão cumulativa cada vez maior. Entretanto, para Ribeiro (1977) a Administração Acadêmica ou Universitária tem oferecido um tratamento mais científico ao exercício de suas funções.

Para Catani, Dourado e Oliveira (2001), a questão da organização acadêmica e gestão vem se tornando uma temática importante nas pesquisas e reflexões da área, não se restringindo aos momentos de efervescência decorrentes do anúncio de estudos, propostas ou implementação de políticas que alterem a natureza jurídica e a configuração das instituições de educação superior.

As funções de Administração Acadêmica podem ser classificadas em: funções substantivas e funções auxiliares ou adjetivas. As funções substantivas, englobam todas as atividades desempenhadas desde o ingresso do estudante na Universidade até a sua certificação. Nesse intervalo estão incluídas, as matrículas que o aluno efetua a cada período letivo, as verificações de aprendizagem a que se submete e a integralização do currículo do curso respectivo. As funções substantivas, de acordo com Ribeiro (1977) são: a) admissão; b) matrícula; c) integralização; d) avaliação; e, e) certificação.

Já as funções auxiliares ou adjetivas são as que criam as condições indispensáveis ao bom desempenho das atividades-fim da Administração Universitária. Envolvem o controle do espaço no qual são desenvolvidas as funções acadêmicas; o planejamento da utilização do 
tempo em que essas funções serão efetuadas; o processamento dos resultados e do desempenho discente; a organização dos assentamentos onde serão armazenados esses resultados e todos os instrumentos adotados na formalização do diálogo entre instituição e aluno.

De acordo com o que foi apresentado, emerge que as funções adjetivas da Administração Acadêmica podem ser assim classificadas, de acordo com Ribeiro (1977):

a) administração do espaço acadêmico;

b) planejamento e controle do tempo acadêmico;

c) o processamento da vida funcional discente;

d) a organização dos assentamentos acadêmicos; e,

e) a informação acadêmica.

A tradição empirista que caracteriza a Administração Universitária presume que quem leciona ou tem um determinado nível intelectual também tem a capacidade de administrar e desenvolver todo o complexo conjunto das funções administrativas. A própria universidade, responsável por formar especialistas em Administração para oferecê-los ao mercado de trabalho, não os utiliza como seus administradores. Deste modo, uma reflexão apoiada em fundamentos científicos a respeito dos fenômenos administrativos que envolvem sistemas universitários será benéfica.

A importância e a premência de soluções para os problemas de Administração Escolar são mais ostensivos no que se refere a Administração Universitária, não porque esta trate das atividades funcionais da Universidade, mas, principalmente, porque não tem sido suficientemente estudada para que os administradores e docentes universitários possam ser devidamente orientados (RIBEIRO, 1977).

Campos (2002) lembra ainda que todas as organizações são constituídas de recursos humanos e de recursos materiais. Nelas são produzidos bens e serviços. As organizações são extremamente heterogêneas e diversificadas, de tamanhos, estruturas e objetivos diferentes, não existindo em hipóteses alguma, assim como os indivíduos, duas organizações semelhantes. E uma organização nunca é igual ao longo do tempo. Existem organizações lucrativas ou utilitárias e organizações não-lucrativas ou normativas.

A sociedade é constituída de organizações: ela é basicamente uma sociedade de organizações. Para que as organizações possam ser administradas, elas precisam ser estudadas, analisadas e conhecidas, o que significa elaborar teorias sobre o seu comportamento como resposta de sua interação com o ambiente. 
A Administração Universitária encontra seu fundamento basilar na idéia de liberdade acadêmica. A administração e a liberdade acadêmica estão interligadas de tal forma que o sucesso de uma ou de outra depende da eficácia com que cada qual singularmente será desenvolvida no espaço universitário. Assim, a Administração não pode perder de vista a liberdade acadêmica como princípio norteador de sua estratégia de atuação, "sob pena de esterilizar-se no tempo e instrumentalizar-se institucionalmente a serviço do poder, não como um valor científico próprio que se polariza em torno do homem” (RIBEIRO, 1977, p.8).

A liberdade acadêmica, por sua vez, não poderá se desenvolver plenamente, se não tiver como se apoiar em algum modelo administrativo que lhe ofereça as condições necessárias ao seu exercício. Uma organização universitária que não possui a devida harmonia entre a Administração e a liberdade acadêmica não passará de uma instituição que declara seus princípios no papel, mas não os põe em prática. Em outras palavras, como assegura Ribeiro (1977, p.8) “a Administração Acadêmica deve, assim, desenvolver-se teleologicamente voltada para o seu objetivo último: a criação de condições para o pleno exercício da liberdade acadêmica".

No entanto, para que a Administração Acadêmica não se deixe envolver por modelos enganosos, desenvolvidos e implantados em nome de princípios aparentemente democráticos é necessário ter sempre em mira a natureza da liberdade acadêmica, sua conceituação e suas dimensões mais gerais.

A liberdade acadêmica encontra suas bases institucionais na própria concepção liberal de Universidade. Ela não pode se tornar um privilégio de grupos, preocupados em proclamá-la ou exigi-la, apenas para assegurar em seu favor garantias de impunidade ou as vantagens de imunidade. Destarte, não pode a liberdade acadêmica ser invocada para garantir a pugilos estudantis o direito de se perpetuarem no poder, ou a dirigentes universitários para se constituírem em oligarquia da administração superior da Universidade.

Ambas as atitudes desfiguram a própria natureza da instituição universitária, tornando-a um ente alienado da sociedade e que serve, a qual tenta impor seus métodos, procurando adaptá-lo aos gostos e anseios de seus dirigentes (RIBEIRO, 1977).

A política de educação superior no Brasil tem como eixo central a Lei de Diretrizes e Bases da Educação Nacional (LDB), de 20 de dezembro de 1996 (Lei nº 9.394/96) e alguns artigos da Constituição Federal de 1988. Juntamente com outros instrumentos legais relevantes, a LDB e Constituição Federal, promoveram a completa reestruturação da educação superior. 
Para Catani e Oliveira (2002) essa reestruturação caracterizou-se em um processo que restringiu a atuação da esfera pública e ampliou a ação do setor privado, alterando de maneira significativa a identidade das instituições de ensino superior. Esse processo teve como resultado a educação transformada em "produto", que os "clientes" adquirem no mercado universitário.

O Brasil possui um sistema de ensino universitário bastante heterogêneo, complexo e diversificado. Neste sentido, Catani e Oliveira (2002) afirmam que as instituições de ensino superior públicas constituem-se como objeto de amplo controle social, incluindo-se aí as avaliações interna e externa.

No entanto, é necessário assegurar que essa parcela do sistema de ensino, como bem social a serviço do bem comum mantido com recursos governamentais, deva procurar contribuir para o desenvolvimento do país como um todo, reduzindo as desigualdades regionais, difundindo o saber entre especialistas e entre os vários segmentos do tecido social (CATANI E OLIVEIRA, 2002).

Contudo, o que pode ser observado a partir da reestruturação promovida pela legislação vigente, afirma Catani e Oliveira (2002), não é um avanço significativo da educação pública e da inclusão social; mas, ao contrário, tende-se para o aprofundamento da apartação social entre a minoria incluída e a maioria cada vez mais excluída da sociedade da informação e do conhecimento.

A Administração Universitária insere-se neste complexo sistema que caracteriza o ensino superior no país. Para Reis (2003) a complexidade do sistema de ensino superior, entre outras coisas, determina a compreensão das políticas que o regulamenta, o papel das instituições de ensino superior na sociedade e métodos de administração compatíveis com a diversidade de demandas existentes.

Em presença da expansão da oferta de vagas e cursos, da concorrência pelo mercado, das exigências dos padrões de qualidade do MEC, das diretrizes curriculares que redirecionam os princípios de organização das graduações, as instituições de ensino superior necessitam repensar as finalidades da educação superior como um todo.

Os Centros Universitários, sustenta Reis (2003, p. 74), representam uma modalidade de instituição que ainda não consolidaram sua identidade e finalidade. A administração e a gestão universitária constituem um instrumento que viabiliza o entendimento das complexidades do sistema de ensino. É essencial conciliar os princípios da gestão, a consolidação da eficácia e eficiência das instituições de ensino superior com atitudes e 
convicções que devem caracterizar o ensino superior: "a produção do conhecimento em benefício do homem, a educação como elemento de desenvolvimento sustentável e de justiça social".

Dentro desse ínterim, é função dos administradores compreenderem a dinâmica e a estrutura do ensino superior e suas especificidades. Entre os elementos dessa dinâmica existe a diversificação do sistema de ensino no que diz respeito a tipologia de instituições, a oferta de novas modalidades de cursos (ensino a distância, cursos seqüenciais, mestrado profissional, entre outros), as demandas advindas das diretrizes curriculares e a variedade de soluções e portarias do MEC.

De tal modo, o processo de decisão, implementação e avaliação nas instituições de ensino superior necessita ser agilizado, visto que a capacidade de conciliar informações, para então sistematizá-las e transformá-las em ações, representa o compromisso dos administradores no intento de alcançar a eficiência nos processos internos da universidade. Tomar conhecimento do ambiente interno e externo da instituição facilita o processo de decisões e propicia uma visão sistêmica (REIS, 2003).

Reis (2003) defende também que o fundamento que deve nortear a gestão universitária é o enfoque sistêmico, para que os subsistemas mantenham-se integrados, e para que a missão, visão e valores da instituição de ensino superior sejam incorporados e difundidos. Deste modo, é possível evitar a dispersão nos investimentos, conciliando o planejamento estratégico da instituição com o compromisso de educação.

É importante que a integração torne-se um objetivo comum e que as diversas demandas possam ser analisadas pelos gestores. Essa questão é essencial, uma vez que conciliar "maior qualidade", clientes satisfeitos, maior lucro e mais investimentos representa a possibilidade de interação entre a missão institucional e o compromisso com os resultados. Nessa dinâmica, a avaliação institucional desempenha um papel fundamental, pois apresenta os indicadores dos processos internos, apontando as forças e fraquezas (REIS, 2003).

Ademais disso, as instituições universitárias precisam de uma administração que assegure a manutenção de sua concorrência, para que a interferência do mercado não corroa a sua capacidade de investimento. A visão empreendedora juntamente com a capacidade de análise do processo de globalização e de implementação de mudanças são fatores substancias para o sucesso da gestão universitária.

Sabendo-se de que a expansão do ensino superior, desperta o debate sobre sua finalidade e qualidade também é importante questionar qual o papel das instituições de ensino 
superior dentro da sociedade. Isso requer o conhecimento das políticas governamentais, das demandas sociais e da vontade de superação dos modelos de administração burocráticos e focados em objetivos distantes do desenvolvimento social sustentável (REIS, 2003).

Acerca deste assunto, cumpre destacar:

A proliferação do ensino tende a intensificar a necessidade e ampliar o papel dos gestores, pois o compromisso da instituição de ensino superior vai além do ensino, extensão e pesquisa, suas responsabilidades são com a sociedade, ciência e tecnologia. O gestor deve ter habilidades: capacidade de relacionamento, de conhecimento sobre os fundamentos da gestão (capacidade intelectual para pensar as especificidades do cargo), compreensão das tendências e rumos do ensino superior, de relacionamento político para articular os programas, projetos, objetivos e metas da instituição de ensino superior e, sólida formação cultural, humana e ética (REIS, 2003, p.89).

Em suma, de acordo com Reis (2003) a universidade caminha para um momento decisivo: a necessidade de que a gestão se efetive com uma abordagem estratégica como elemento de superação das debilidades organizacionais. Essa gestão é entendida como uma forma de administração que se fundamenta no paradigma sistêmico e que, portanto, está atenta para as necessidades dos vários atores presentes nos ambientes interno e externo da universidade.

Destarte, superar os reptos, perceber as tendências da educação superior, construir cenários, investir nas pessoas e compreender as demandas de uma sociedade que valoriza o conhecimento e que está em constante transformação, são condições de sucesso para a instituição de ensino superior, cuja conquista está diretamente relacionada com o modelo de gestão adotado (REIS, 2003).

\section{CONSIDERAÇÕES FINAIS}

Sobremodo interessa ponderar, à luz do alvitre de Mandelli; Lucas; Viveiros; Pierrotti; Loriggio; Ayres (2003), que as organizações evoluem e se revolucionam em um efeito de vai-e-vem de centralização/descentralização, no qual a solução de uma fase é a geradora da crise da seguinte e assim por diante. Cada nova solução cria espaço para crescimento e desenvolvimento em um ciclo em que centralização e descentralização são problemas e soluções dependendo da maturidade e da evolução da organização.

Alicerça-se no alvitre da lavra de Kotter (1997) que afirma ser extremamente difícil realizar grandes transformações, por isso torna-se necessária uma força vigorosa para 
sustentar o processo. Nenhum indivíduo isolado, nem mesmo um poderoso executivo principal, é capaz de desenvolver a visão correta, comunicá-la a um grande número de pessoas, eliminarem todos os obstáculos-chave, possibilitar vitórias a curto prazo, liderar e gerenciar dezenas de projetos de mudança e, ainda, enraizar novas abordagens na cultura da organização. Comissões fracas, ainda buscando apoio em Kotter (1997), são ainda piores. Uma coalizão administrativa forte sempre se faz necessária - uma coalizão com pessoas, nível de confiança e objetivos comuns adequados. A elaboração dessa equipe é sempre um ponto fundamental nas fases iniciais de qualquer esforço de reestruturação, reengenharia e a reformulação de um conjunto de estratégias.

Os estudos sobre as decisões na universidade estão longe de exaurimento, há necessidade de maior aprofundamento nas variáveis e dimensões estudadas por diversos pesquisadores que concluíram que tanto o modelo político como o burocrático eram significativos e que o modelo de coalizão se fundamenta porque operam em concomitância em muitas decisões, lutando por interesses tanto por força política como por regras burocráticas.

Dias (2008) assevera que as organizações vivem diuturnamente dilema a respeito da mudança planejada. Por um lado, desejam mudar para manter a competitividade para adotar mais eficácia e eficiência, e continuar em harmonia com seu ambiente externo. Por outro lado, com freqüência, resistem à mudança devido ao seu desejo por uma relativa estabilidade e previsibilidade.

A resistência ocorre entre os membros de uma organização, principalmente, por temor à mudança e ao que ela significará em termos de alteração da sua atual situação. Preocupações em torno de se haverá alteração salarial, modificação de status, perda de poder ou de prestígio e até mesmo perda do emprego são alguns dos temores que surgem quando aparece a perspectiva de mudança nas organizações. Esses temores se traduzem em resistência à mudança Dias (2008).

O modelo burocrático com regras universais de maximização e eficiência na busca de objetivos específicos e o modelo de coalizão refletem, além de regras formais e universais, também a prática empresarial.

Para Weber o termo burocracia não tem o significado pejorativo de uso popular, mas um significado técnico que identifica certas características da organização formal voltada exclusivamente para a racionalidade e para a eficiência, descrevendo a burocracia como um "tipo ideal" de estrutura. 
As organizações em sua fase inicial apóiam-se na formalização do comportamento para obter um maior grau de controle e coordenação e pode-se chamar de burocracia. Percebese que independente do porte da organização e de sua atividade a formalização de comportamentos ou, também, de procedimentos, estão presentes nos diversos meios de comunicação (normas, regulamentos, manuais e outras fontes de controle).

A burocracia constitui estrutura formal e racionalmente organizada, onde todas as atividades estão funcionalmente relacionadas aos propósitos gerais da organização. $\mathrm{O}$ alto grau de formalização e os rígidos procedimentos dificultam e restringem uma passagem rápida do mundo das idéias (impulso) à decisão (ação). Estas características estruturais somadas a uma cultura organizacional, que inibe a criatividade e defende a manutenção do estado das coisas, fazem com que as mudanças se dêem de forma lenta.

Para Rocha Neto (2004), um novo paradigma técnico-econômico está produzindo importantes e crescentes implicações às universidades, instituições de ensino e aos institutos de pesquisa. A globalização da economia e o aumento da concorrência internacional reforçam a importância da dimensão tecnológica da competitividade.

Essa condição tem implicado na necessidade de as empresas buscarem uma maior aproximação com as universidades e institutos de pesquisa tecnológica para atendimento de suas demandas, no sentido de viabilizar a exploração econômica de oportunidades de mercado, que se caracterizam pelo deslocamento da produção, padronizada e de larga escala, à oferta de bens e serviços de alto valor.

Em consonância o com o magistério da lavra de Rocha Neto (2004) entrementes em que este novo cenário gera novas oportunidades para universidades e institutos, também impõe um enorme esforço de adaptação aos novos tempos e de capacitação tecnológica para viabilizar ao atendimento dessas demandas. No alvitre de Finger (apud SILVEIRA; COLOSSI; SOUSA, 1998), a educação, em totalidade, passou a ser a atividade mais significativa no mundo moderno, quer pelo número de pessoas que com ela estão envolvidas, quer pelo montante de recursos gerados ou necessários para a operação das instituições ou sistemas.

A educação superior, neste contexto, amealha especial destaque por representar o nível mais alto de formação e produção de conhecimento. Instituição inatacável até anos recentes, a universidade passou a ser objeto de análise e preocupação de pesquisadores e cientistas de diferentes áreas. Esse é um processo novo e tem apresentado trabalhos significativos de análise e propostas para a melhoria das organizações. A Universidade 
brasileira normalmente tem característica estrutural formalizada por colegiados e conselhos, onde se busca um padrão de procedimentos através das resoluções e regulamentações internas. A universidade é considerada uma organização complexa por sua condição de instituição especializada, com objetivos diversificados e imprecisos, executora de tarefas múltiplas. Suas funções de ensino, pesquisa e extensão, interdependentes embora, requerem uma organização diferenciada e se relacionam com o ambiente externo à universidade.

Por fim, cumpre concordar com Choo (2006), de acordo com o qual, malgrado sejam quase sempre tratadas como processos independentes de informação organizacional, as três arenas de uso da informação - criar significado, construir conhecimento e adotar decisões são de fato processos interligados. Por cosneguinte, analisando como essas três atividades se alimentam mutuamente, teremos uma visão holística do uso da informação, sendo que a organização que for capaz de integrar eficientemente estes processos pode ser considerada uma organização do conhecimento.

\section{REFERÊNCIAS}

ABRAHMSON, Eric. Mudança organizacional: uma abordagem criativa, moderna e inovadora. São Paulo: Makron Books, 2006.

ALPERSTEDT, Cristiane. As universidades corporativas no contexto do ensino superior. Tese de Doutorado, FEA/USP, 2001.

AMBONI, Nério; TEIXEIRA, Rômulo dos Santos. O papel do líder frente ao processo de transformação organizacional: uma discussão preliminar. In: HÉKIS, Hélio Roberto; OLIVEIRA FILHO, Ary; AMBONI, Nério; HAWERROTH, Jolmar Luis; TEIXEIRA, Rômulo dos Santos (coord.). Gestão empresarial: casos e resenhas. Florianópolis: Conceito Editorial, 2008.

BOOG, Gustavo. Manual de treinamento e desenvolvimento. ABTD. São Paulo: MAKRON Books, 1999.

CAMPOS. Celso. A organização inconformista: como identificar e transformar mentes revolucionárias em um diferencial competitivo. 2ª . ed. rev. Rio de Janeiro: Ed. FGV, 2002.

CATANI, Afrânio Mendes; OLIVEIRA, João Ferreira de. A educação superior. OLIVEIRA, Romualdo Portela de; ADRIÃO, Theresa (orgs.) Organização do ensino no Brasil: níveis e modalidades na Constituição Federal e na LDB. São Paulo: Xamã, 2002.

CATANI, Afrânio Mendes; DOURADO, Luiz Fernandes; OLIVEIRA, João F. Natureza jurídica, organização acadêmica e gestão universitária. In: SGUISSARDI, Valdemar; SILVA Jr., João dos Reis. Educação superior: análise e perspectivas de pesquisa. São Paulo: Xamã, 2001. 
CERVO, A. L e BERVIAN, P. A. Metodologia científica. São Paulo: McGraw Hill,1983. CHOO, Chun Wei. A organização do conhecimento: como as organizações usam a informação para criar significado, construir conhecimento e tomar decisões. $2^{\mathrm{a}}$. ed. São Paulo: Ed. Senac, 2006.

COLOSSI, Nelson. A dicotomia crise mudança no comportamento de instituições de ensino superior. In: COLOSSI, Nelson; PINTO, Marli Dias de Souza. Estudos e perspectivas em gestão universitária. Blumenau: Nova Letra, 2004.

DEMO, Pedro. Conhecimento Moderno - Sobre ética e intervenção do conhecimento. Petrópolis: Vozes, 1999.

DEMO, Pedro. Questões para a Teleducação. Petrópolis: Vozes, 1998.

DIAS, Reinaldo. Sociologia das organizações. São Paulo: Atlas, 2008.

DIBELLA, Anthony J.; NEVIS, Edwin C. Como as organizações aprendem: uma estratégia voltada para a construção da capacidade de aprendizagem. São Paulo: Educator, 1999.

DRUCKER, Peter F. O melhor de Peter Drucker: o homem, a administração, a sociedade. São Paulo: Nobel, 2001.

FIALHO, Francisco Antonio Pereira; MONTIBELLER FILHO, Gilberto; MITIDIERI, Tibério da Costa. Gestão da sustentabilidade na era do conhecimento: o desenvolvimento sustentável e a nova realidade da sociedade pós-industrial. Florianópolis: Visual Books, 2008.

GRECO, Milton. Educação superior para a construção de projetos de vida. São Paulo: Editora Salesiana, 2002.

GUEDES, Enildo Marinho. Curso de metodologia científica. 2a . ed. Curitiba: HD Livros, 2000 .

GUIMARÃES, Geraldo; RECHTMAN, Marcos; NETTO, Roberto Lima. Nova estrutura: reinventando sua empresa. Rio de Janeiro: Ed. FGV, 2004.

KANAANE, Roberto. Momento humano nas organizações: o homem rumo ao século XXI. São Paulo: Atlas, 2000.

KATZ, Fremont E.; ROSENZWEIG, James E. Organização e Administração. $2^{a}$ ed. São Paulo: Livraria Pioneira Editora, 1980.

KAUFMANN, Arnold. A Ciência da Tomada de Decisão. 2a ed. Rio de Janeiro: Zahar Editores, 1981.

KOTTER, John P. Liderando mudança. 16a . ed. Rio de Janeiro: Elsevier, 1997.

LAKATOS, Eva Maria. Sociologia da Administração. São Paulo: Atlas, 1997. 
LAMPERT, Ernani. A universidade e a pesquisa. In; LAMPERT, Ernani (org. Universidade na virada do século 21: ciência, pesquisa e cidadania. Porto Alegre: Sulina, 2000.

LEITÃO, Sérgio Proença. A Decisão na Academia I. Revista de Administração Pública. Rio de Janeiro: Fundação Getulio Vargas, 27(1):69-86, jan./mar., 1993. (a)

LISBÔA, Maria da Graça Cavalcanti. A idéia de universidade no Brasil. Porto Alegre: Est, 1993.

MANDELLI, Pedro; LUCAS, Reinaldo; VIVEIROS, Cláudio; PIERROTTI, Francisco; LORIGGIO, Antônio; AYRES, Luiz. A disciplina e a arte da gestão das mudanças nas organizações: como integrar estratégias e pessoas. 8 $^{\text {a }}$. ed. Rio de Janeiro: Campus, 2003.

MINTZBERG, Henry. Criando organizações Eficazes: estruturas em cinco configurações. São Paulo: Atlas, 1995.

MOHRMAN, Susan A., MOHRMAN JR., Allan M. Mudanças Organizacionais e Aprendizado. In: GALBRAITH, Jay R., LAWER III, Edward E. e Associados (org.)

Organizando para competir no Futuro. São Paulo: MAKRON Books, 1995.

MORGAN, Gareth. Imagens da Organização. São Paulo: Atlas, 1996.

MORITZ, Gilberto de Oliveira; PEREIRA, Maurício Fernandes. Processo decisório. Florianópolis: SEAD/UFSC, 2006.

MUNIZ, Adir Jaime de Oliveira; FARIA, Hermínio Augusto. Teoria geral da administração: noções básicas. São Paulo: Atlas, 2001.

PACHECO Jr, Waldemar; PEREIRA, Vera Lúcia Duarte do Valle; PEREIRA FILHO, Hyppólito do Valle. Pesquisa científica sem tropeços: abordagem sistêmica. São Paulo: Atlas, 2007.

PARK, Kil H (Coord.). Introdução ao estudo da administração. São Paulo: Pioneira, 1997.

PENIN, Sonia T. Sousa; VIEIRA, Sofia Lerche. Refletindo sobre a função social da escola. In: VIEIRA, Sofia Lerche (Org.) Gestão da escola: desafios a enfrentar. Rio de Janeiro, DP\&A, 2002.

PEREIRA, Maria José Lara de Bretãs; FONSECA, João Gabriel Marques. Faces da Decisão: as mudanças de paradigmas e o poder da decisão. São Paulo. Makron Books, 1997.

RAIMUNDO, Paulo Roberto. O que é administração. São Paulo: Brasiliense, 1992. (Coleção Primeiros Passos)

REIS, Fábio José Garcia dos. Perspectivas da gestão universitária. Taubaté: Cabral Editora e Livraria Universitária, 2003.

RIBEIRO, Nelson de Figueiredo. Administração acadêmica universitária: a teoria, o método. Rio de Janeiro: Livros Técnicos e Científicos, 1977. 
ROCHA, Ivan. Gestão de organizações de conhecimento. Brasília: FUNADESP, UCB/Universa, 2004.

ROMANELLI, Otaíza de Oliveira. História da educação no Brasil. 13. ed. Petrópolis: Vozes, 1991.

SANTOS, Clóvis Roberto dos. O gestor educacional de uma escola em mudança. São Paulo: Pioneira, 2002.

SCHARF, Edson Roberto. Gestão do conhecimento aplicada ao marketing: como usar conhecimento e ações orientadas para o mercado no desenvolvimento de vantagens competitivas sustentáveis. Florianópolis: Visual Books, 2007.

SILVEIRA, Amélia; COLOSSI, Nelson; SOUSA, Claudia Gonçalves de. Administração universitária: estudos brasileiros. Florianópolis: Insular, 1998.

STONER, James A. F. Administração. Rio de Janeiro: Prentice Hall do Brasil, 1985.

TEDESCO, Juan Carlos. Educar na sociedade do conhecimento. Araraquara: Junqueira e Marin Editores, 2006.

VASCONCELOS, Flávio Carvalho de. Dinâmica organizacional e estratégia: imagens e conceitos. São Paulo: Thomson Learning, 2007.

VASCONCELOS, Isabella F. Gouveia de; MASCARENHAS, André Ofenhejm. Organizações em aprendizagem. São Paulo: Thomson Learning, 2007.

WEBER, Max. Burocracia. In: GERTH, Hans; MILLS, Charles Wright (Orgs.). Ensaios de sociologia. 5. ed. Rio de Janeiro: Guanabara, 1982.

WEBER, Max. Os fundamentos da organização burocrática: uma construção do tipo ideal. In: CAMPOS, Edmundo (Org.). Sociologia da burocracia. 4. ed. Rio de Janeiro: Zahar, 1978.

XAVIER, Ricardo de Almeida Prado. Capital Intelectual: administração do conhecimento como recurso estratégico para profissionais e organizações. São Paulo: Editora STS, 1998. 